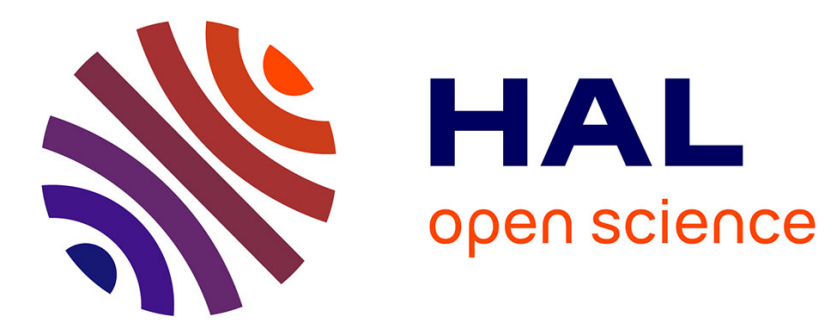

\title{
Development of an AI-based Rapid Manufacturing advice system
}

Javier Munguía, Joaquim Lloveras, Sonia Llorens, Tahar Laoui

\section{To cite this version:}

Javier Munguía, Joaquim Lloveras, Sonia Llorens, Tahar Laoui. Development of an AI-based Rapid Manufacturing advice system. International Journal of Production Research, 2010, 48 (08), pp.22612278. 10.1080/00207540802552675 . hal-00565388

\section{HAL Id: hal-00565388 https://hal.science/hal-00565388}

Submitted on 12 Feb 2011

HAL is a multi-disciplinary open access archive for the deposit and dissemination of scientific research documents, whether they are published or not. The documents may come from teaching and research institutions in France or abroad, or from public or private research centers.
L'archive ouverte pluridisciplinaire $\mathbf{H A L}$, est destinée au dépôt et à la diffusion de documents scientifiques de niveau recherche, publiés ou non, émanant des établissements d'enseignement et de recherche français ou étrangers, des laboratoires publics ou privés. 


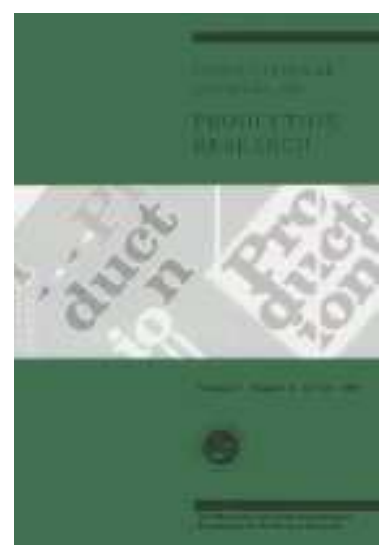

\section{Development of an AI-based Rapid Manufacturing advice system}

\begin{tabular}{|r|l|}
\hline Journal: & International Journal of Production Research \\
\hline Manuscript ID: & TPRS-2008-IJPR-0404 \\
\hline Manuscript Type: & Original Manuscript \\
\hline Date Submitted by the & $19-$ Mathor: 2008 \\
\hline Complete List of Authors: & $\begin{array}{l}\text { Munguía, Javier; Technical University of Catalonia, Engineering } \\
\text { Projects } \\
\text { Lloveras, Joaquim; Technical University of Catalonia, Engineering } \\
\text { Projects } \\
\text { Llorens, Sonia; Industrial Equipment Research Centre (CDEI-UPC), } \\
\text { Research Projects } \\
\text { Laoui, Tahar; KFUPM, Department of Mechanical Engineering }\end{array}$ \\
\hline Keywords: & $\begin{array}{l}\text { RAPID MANUFACTURING, RAPID PROTOTYPING, ARTIFICIAL } \\
\text { INTELLIGENCE, MANUFACTURING PROCESSES }\end{array}$ \\
\hline Keywords (user): & \begin{tabular}{l} 
process selection \\
\hline
\end{tabular} \\
\hline
\end{tabular}

\section{今 scholarONE" \\ Manuscript Central}




\title{
RESEARCH ARTICLE
}

\section{Development of an AI-based Rapid Manufacturing advice system}

\author{
Javier Munguía $^{a^{*}}$, Joaquim Lloveras ${ }^{\mathrm{a}}$ and Sonia Llorens ${ }^{\mathrm{b}}$ \\ ${ }^{\mathrm{a}}$ Technical University of Catalonia, Barcelona Spain; ${ }^{\mathrm{b}}$ Industrial Equipment Research Centre (CDEI) Barcelona, Spain
}

\begin{abstract}
The purpose of this paper is to assess the possibility of using Rapid Manufacturing (RM) as a final manufacturing route through a comparison of RM capabilities vs. conventional manufacturing routes. This is done by means of a computer-aided system intended to guide the designer in the selection of optimum production parameters according to general product requirements proper of the first design stages. The proposed system makes use of a number of Artificial Intelligence (AI) tools namely: fuzzy inference, relational databases and rule-based decision making to reach an optimum solution. A pilot application developed in Matlab® is presented to illustrate the system application on a real mechanical part used as case study.

Along the article it is shown how the proposed model may be useful for presenting feasible RM alternatives for parts and products not originally intended for additive manufacture. It also indicates when no RM alternatives are suitable for the given tasks, thus indicating those areas of knowledge which are necessary to expand in order to have at disposal comprehensive and reliable info on RM to compete with conventional processes.
\end{abstract}

Keywords: Rapid manufacturing, rapid prototyping, process selection, artificial intelligence

* Email: Javier.munguia@upc.edu 


\section{Introduction}

During the product development process, it is important to consider manufacturing issues since the earlier stages in order to achieve reductions on time, costs and improve the quality. According to Ullman (1997) although design represents a rough 5\% of the final product cost, upwards $70 \%$ of total cost is determined in this stage. However an early consideration of manufacturing alternatives during the design stages might bring associated drawbacks. For instance depending on the designer's knowledge on manufacturing processes and materials, available options might be inappropriately narrowed, thus guiding to a non-optimum solution. This selection task during preliminary engineering design is characterized by qualitative descriptions of requirements, imprecise data and complex relationships (Giachetti 1998).

The high number of materials to be evaluated and their combination with different suitable processes leads the designer to rely on his personal experience and apply the options that have provided the most satisfactory results in the past. This gap between the designer's knowledge and available manufacturing technologies might be even increased with the massive introduction of new processes especially in the last decade when most of the currently used additive technologies were launched (Grimm, 2004)

A number of manufacturing decision software is available to help reducing this manufacturing knowledge gap. The Cambridge Materials and process selection (GRANTA 2007) is an example of a comprehensive materials database linked to process compatibility and capacity. Also, addressing the manufacturing and assembly issues of production the software DFMA (Dewhurst 2007) also incorporates a comprehensive materials database coupled with process compatibility and cost analysis although it focuses in the concurrent costing for DFM and assembly. Dieter (Dieter 2000), Shercliff and Lovatt (2001) besides other specialized sources (ASM 1997) contain a more detailed compilation of computer-aided selection for further reading.

Rapid manufacturing technologies are derived from Rapid Prototyping (RP) processes that appeared in the early 90's(Jacobs, 1992). Their principle of additive fabrication to construct complete parts by depositing thin layers of material has grown into a set of technologies suitable for the manufacture of end use products depending on the material, parameters selected and the function to be performed.

Although it has been claimed that RM may cut product development cost by $70 \%$ and time to market by $90 \%$ (Waterman 1991) there are currently no systems available for the assessment of RM technologies as potential manufacturing routes. However there is significative work on automated systems for RP selection.

\subsection{Previous attempts for RP selection}

Rapid prototyping refers to those technologies capable of producing prototypes directly from a CAD source, via layer-wise deposition (Bibb et al., 1999, Masood and Al-Alawi, 2002). The selection of the most suitable RP process is dependent on factors such as build envelope, accuracy, material, build speed and other machine-related parameters. With around 22 manufacturers marketing between 40 and 60 models of RP machines (Wohlers, 2006), the development of computer-based selection systems has been a recurrent topic in RP related literature (Masood and Al-Alawi, 2002).

Probably the first attempt to develop a computer based program for RP selection was made by Hornberger (1993) at Santa Clara University which was mainly used as an academic aid for process selection among those RP processes available by 1993. Other systems based on relational databases 
were introduced by Muller (Muller, 1996), Campbell and Bernie (Campbell and Bernie, 1996). The former was rather focused on finding the best materials- process combination expressed in percentages by applying the so called "Benefit Value Analysis". Later research from this same institution focused on Rapid Tooling techniques within the complete RP process chain. Campbell introduced the RP process capabilities database, which through the use of relational databases was intended to find the best match between RP process capabilities and part features (thin walls, primary shape, holes, bosses, chamfers and other key features).

Later on Phillipson and Henderson (1997) from Arizona State University introduced the RP Adviser also based on relational databases applying Ms Access $®$ (Microsoft, 2005). It made use of mathematical relations and multi-criteria optimization to find the best alternative, besides deploying interviews with experts to check the system's effectiveness.

Knowledge-based expert systems for RP selection were later introduced by Bibb et al. (1999), Bernard (Bernard, 2003), Masood and Soo (2002), the later from the Industrial Research Institute Swinburne (IRIS),Australia. This software was partially based on data gathered from users survey on selection criteria and their own applications to feed the base of knowledge, however, in despite of its comprehensive databases the system still lacks of cost, materials and build time information since it's intended for equipment selection for purchase. Lan et al. ( 2005) introduced the Fuzzy synthetic evaluation method for the treatment of quantitative and quantitative data for comparison and weighting purposes. It splits criteria factors in: Technology, Geometry, Performance, Economy and Productivity considering a pair of factors for each process in order to compare them. Nevertheless the final result provides a RP ranking process similar to previous systems which lack of further information on costs, materials or build time.

The Helsinki University of Technology (Helsinki University of Technology, 2002) launched its RPselector based on a series of 12 questions requiring user input on part accuracy, layer thickness, geometric features, requirements, etc. There is also a scaling factor to be selected for each question which makes the system hard to complete for a single analysis. Another web-based RP selection tool was launched by the Industrial Research and Development Corporation (Ivf Sweeden, 2005),which trough only three questions: material/function, quantity, end use requirements, presents a window containing series of recommended processes and their additional information. A definitive ranking is not included however this is one of the only programs to include Rapid Tooling as an option.

Following the web based approach the Spanish Rapid Manufacturing Association ASERM (ASERM, 2006) recently launched a RP selector which clearly distinguishes between two options: the use of additive processes for prototype construction and the use of rapid tooling methods for final parts and pre-series. However the system still lacks of costing, materials information and a more comprehensive input since it's based basically in generic data regarding the part's build volume, overall tolerance and type of material.

The systems described above may not be valid for assessing the manufacturing feasibility trough $\mathrm{RP} / \mathrm{RM}$ technologies due to the following reasons:

a) None of the existing systems provides economic assessment for any RP alternative

b) The RP process capabilities are only compared among additive processes and not extrapolated to be compared with those of conventional technologies.

c) Databases developed for RP materials and machine parameters are not comprehensive enough to allow for RM assessment. More cases need to be developed and documented. 
This paper proposes an integrated RM selection system that integrates an expert system, a fuzzy inference engine and databases in order to support quantitative and qualitative data. In addition the concept of "critical multipliers" is introduced which refers to those critical conditions that must be fulfilled for a certain task (e.g. critical structural part, insulating material, flame retardant, etc.). The non-fulfilment of any of those conditions may lead to the multiplication of the final vector by 0 , automatically discarding the respective process. The final goal is not the fabrication of a prototype but the identification of RM alternatives as feasible manufacturing options.

\section{The system's architecture}

The Rapid Manufacturing advice system (RMADS) is intended to support designers during the earlier design stages to asses the possibility of using RM as a valid manufacturing route. It uses state of the art knowledge on RP/RM besides a series of previous case studies for verification purposes (Mahesh, 2005, Lan, 2005, Jiang and Hsu, 2003). Moreover a knowledge base obtained from local users, service bureaus and engineering centres (Munguía, 2007)) is used in order to capture preferences and usual practices during design for RM. The RMADS architecture is shown in Figure 1. It shows the different modules working together with data extracted from two main databases to support the decision making task. The model is based on an object-oriented methodology (Masood and Al-Alawi, 2002) i.e. it is capable of working with independent modulus performing event-driven calculations according to user selection.

Figure 1. RMADS architecture and its main blocks

\subsection{The elements of the RMADS system}

System interface: The user interface supports numerical values and linguistic terms that are chosen from a pre-defined list for every design attribute. As a result activated option will lead to the development of a vector with values normalized to the range 0-1 depending on the parameter selected.

Expert system and its Rule-base: The expert's knowledge is represented as a series of IF-THEN -ELSE statements. A total of 500 rules are executed when all the options of the system are activated, however the number of rules is due to increase with every new material and process added to the database. The importance of each rule is defined by the type of data handled as is explained in the following section.

Fuzzy inference system: This stage basically consists of representing all the goals and constraints as fuzzy sets (Zimmerman, 1991) obtained by mapping the membership values based on the selection of linguistic variable by the user (Mahesh, 2005). Depending on the variable chosen (e.g. Surface Roughness, Tolerances, Mechanical properties, etc) the user will be presented a number of suitable options (e.g. high/average/low, etc.),

Different strategies have been implemented in order to translate linguistic terms into fuzzy numbers. Chen and Hwuang (1992) proposed a numerical approximation method to systematically convert linguistic terms to their corresponding fuzzy numbers based on a 11-point scale, while Rao and Padmanabhan (2007) and Chen (1997) proposed a reduced scale expressed in five grades.

During the first tests of the RMADS interface its was suggested by users that multiple choices for a large number of parameters might guide to a long confusing selection procedure therefore for the RMADS system a range comprised of three grades will be used for each parameter. 
Database: Two different databases store data regarding 1) RM Process parameters and individual machine information. 2) Materials database. Data has been gathered from available vendors info, related literature (ASERM, 2006, CASTLE-ISLAND, 2007, eFunda, 2007) as well as from other electronic data (Matweb, 2008, GRANTA, 2007). Data is stored in an Ms Access $®$ database and called from the system by the Matlab® database toolbox (Mathworks, 2006).

Aggregation and ranking module: This module performs the final decision based on the parameters and options selected. Since qualitative information is normalized to 1 and qualitative information is treated with fuzzy numbers, the function of this module is to perform a fuzzy-decision. Although there exist a number of different approaches for ranking fuzzy sets (Carlsson, 1996, Raj and Kumar, 1999) each one with different advantages and drawbacks, for this paper the transformation method(Lan, 2005) is applied.

\subsection{Model description}

Figure 2. The proposed Rapid Manufacturing Advice System algorithm

Methods based on fuzzy logic have been previously used in order to provide a uniform way of ranking different criteria during process/material selection (Bréchet et al(Brechet, 2001). Lan and Ding (2005) go much further to state that it may be also considered a multi-alternative fuzzy decision-making problem. The RMADS system is intended to aid the designer on making appropriate decisions in presence of multiple attributes by following a straightforward procedure:

1. Input information is accepted, normalized and converted to fuzzy numbers.

2. Corresponding vectors are formed for each process. The size of the vector depends on the number of attributes selected as shown in Figure 2.

3. Vectors are ranked according to the aggregation results.

\section{Types of input parameters}

Determining the correct input for the system is important for creating a more robust selection tool however this task is rarely straightforward. According to previous systems for RP selection (Bibb et al., 1999, Shercliff and Lovatt, 2001, Masood and Al-Alawi, 2002, Campbell and Bernie, 1996). Necessary input parameters are the classified by their type in:

- Design related. Design information and specifications (dimensions, volume, shape, surface finish, etc.)

- Production related. Parameters required for further cost estimation (required batch size, production rate)

- Processing and materials related. Depend on process specific parameters (scanning speed, laser spot diameter, chamber temperature, etc.) and materials specific properties (tensile strength, tensile modulus, elongation, impact, wear resistance, etc.)

Previously developed computer based Rapid prototyping selection systems take into account a number of input factors attending the main requirements of these additive type technologies. Table 1 shows a number of parameters included as a system input by some previous RP selection tools. 
Table 1 Input parameters considered by different RP systems

Through a search of conventional process \& materials selectors commercially available (Dewhurst, 2007, GRANTA, 2007, TeamSet, 2005) along with the previous information it was possible to define a number of common parameters for conventional and RP/RM processes. These will be used as the RMAD system input as shown in Figure 3.

Figure 3. The 4 main categories for parameter input and its data type

The main decision criteria are divided into 4 main subjects: Geometry, Appearance, Mechanical Requirements and Functional requirements each of them with different types of data used which receive different treatment:

\subsection{Quantitative data $(Q)$}

It is also the most discriminating type since the non-completion of its requirements may result in the process being ruled out of the selection.

This data is processed by means of an expert rule base for each parameter. The rule base has been developed with the aid of process databases, previous papers results, as well as with observation and expert consultancy during field testing.

Figure 4. Sample rule for the expert system

Data used as "critical multiplier" is comprised of the following parameters:

- Material type

- Part vs. machine build volume

- Max service temperature

- Critical structural parts

- Sanitary requirements

- Fire retardant material needed

- Electrical conductivity needed

When activated, the corresponding operations determine whether a value 1 or 0 will be assigned; When 0 is assigned it causes the respective process ranking to be multiplied by 0 , hence invalidating a certain process in accomplishing that function. The vector formed is as shown in Figure 2.

\subsection{Normalized qualitative criteria $(N Q)$}

Information for these parameters is generally presented in variable terms depending on the data source, for instance the definitions of Surface Roughness found in different sources may be different, e.g.: comparative ratings (A, B, C,D,E) with A indicating the highest value and $E$ the lowest (ASM, 1997) actual numeric values in Ra $\mu \mathrm{m}$ (Ashby, 2005) or Ra $\mu$ in (Boothroyd, 1883) qualitative grades like Good/Average/Bad (ASERM, 2006). Therefore for attributes of this type it is preferred to assign Linguistic terms in order to generalize and appropriately represent this imprecise data for selection. These linguistic terms are then converted to fuzzy numbers following the procedures described in Figure 5a. 
Let a fuzzy number in R be a fuzzy subset in the universe of discourse X. A fuzzy set is represented by stating its membership function (Byun and Lee, 2005). A fuzzy set with a triangular membership function is represented as a triangular fuzzy number defined by variables $(\mathrm{a}, \mathrm{b}, \mathrm{c})$, and $(\forall x, a, b, c \in R)$ then the membership function $\mu_{\tilde{\AA}}(x)$ is defined as in Figure 5b. Following the function depicted above, linguistic variables used in the system are presented in Table 2.

Figure 5 Linguistic term converted to fuzzy numbers by means of a triangular membership

Table 2. Fuzzy numbers assigned for different Linguistic Variables

\subsection{Normalized qualitative criteria $(N Q)$}

This type of input information is called "individual" since it's not possible to apply uniform linguistic terms and the same membership function for each parameter as in the previously case. Instead the following steps are followed:

a) Data collection from databases \& datasheets for conventional process capabilities. This step allows for setting the appropriate universe of discourse (X axis) for the different parameters used. As shown below for Tolerance, the maximum values will be dictated by Sand casting although the rest of the processes perform clearly better.

Figure 6. Tolerance levels for different conventional manufacturing routes

b) Classification of the process information. From the same data sources and consultancy with experts, information is divided in three main values. As in the previous example, the three tolerance grades will be:

- Tight: $\mathrm{T}<=0.1 \mathrm{~mm}$

- Average: $0.1<\mathrm{T}<0.25 \mathrm{~mm}$

- Loose: $\mathrm{T}>0.25 \mathrm{~mm}$

c) Mapping Rapid Manufacturing process information onto conventional processes values. This is useful to understand until which point a certain RM option can perform equally or even outperform other conventional routes.

Figure 7. Rapid Manufacturing options mapped on a similar scale as conventional manufacturing

d) Establish membership functions and crisp data for original information.

In order to assign fuzzy numbers to Individual qualitative data, a trapezoidal function for mapping the fuzzy membership will be used due to its effectiveness and suitability to our case. In the same way, membership grades are assigned to three linguistic variables as defined before.

As shown in Figure 5 the $\mathrm{X}$ axis or universe of discourse will be defined by the parameter values corresponding to conventional manufacturing processes and not to maximum values of RP processes as is the case of earlier RP selection systems.

For the Tolerance parameter, the linguistic variable set \{Tight, Average, Loose represents the crisp values used for the corresponding trapezoidal membership function. In order to get the maximum performance out of competing RP/RM processes a strategy called "positive discrimination" is introduced (Rao and Padmanabhan, 2007), where depending on the parameter selected the 
appropriate lower or uppermost value of the range will be converted to a fuzzy number instead of taking the mean value or triangular number. For instance, if the attribute "Tight" is selected for the tolerance parameter, the lowest value will be assigned (Figure 8a), in the same way if the option "Loose" is selected, the uppermost value will be used(Figure 8c ), while the average value (Figure 8b) will correspond to the middle selection.(Figure 8).

Figure 8. Trapezoidal membership function applied to Tolerance attribute range of SLS

\section{Aggregation and ranking of selected objectives}

Once the decision maker has selected the desired parameters by choosing the appropriate linguistic terms or by introducing data, the system builds one parameter vector for each competing process. This vector is the aggregate of fuzzy numbers obtained from NQ and IQ data as shown in Figure 9.

Figure 9. Initial aggregated Matrix of fuzzy numbers

Since not all the included parameters have the same importance for all design cases, the user is requested to grade from 1 to 4 the main categories according to the importance given for a specific task: Geometry, Appearance, Functionality, and Mechanical Properties where 1 corresponds to the most important factor and 4 for the least important. This leads to the creation of the weighting factor vector W a shown in (1)

$$
\mathrm{W}=(\mathrm{w} 1, \mathrm{w} 2, \mathrm{w} 3 \mathrm{w} 4)
$$

According to Chen (Chen, 1992) the numeric scale entered by the user can be converted to fuzzy numbers following the triangular membership for a 4 point scale as shown in Figure 10.

Figure 10. Fuzzy number conversion for a 4 point scale

Since the final selection will be comprised of 4 main categories, the aggregation matrix G is divided in 4 matrices which are normalized and then multiplied by $\mathrm{W}$ in order to perform the ranking procedure. For instance the Matrix corresponding to the Appearance factor that is comprised of two IQ parameters and $1 \mathrm{NQ}$ for each process as illustrated in (2)

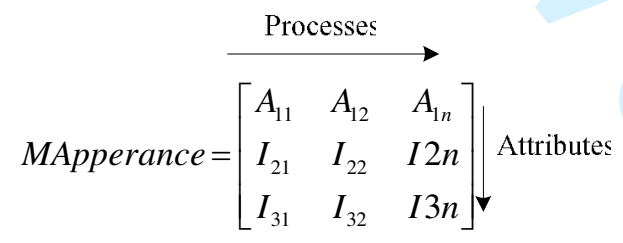

The corresponding fuzzy numbers for the 3 attributes are then added for each process in order to get a final fuzzy grade. The same procedure is followed for the other 3 factors (3).

$$
\begin{aligned}
& \sum \text { MApperance }=\left[\begin{array}{lll}
S 11 & S 12 & S 1 n
\end{array}\right] \\
& \sum \text { MGeometry }=\left[\begin{array}{lll}
S 21 & S 22 & S 2 n
\end{array}\right] \\
& \sum M \cdot \text { properties }=\left[\begin{array}{lll}
S 31 & S 32 & S 3 n
\end{array}\right] \\
& \sum M F \text { unctionality }=\left[\begin{array}{lll}
S 41 & S 42 & S 4 n
\end{array}\right]
\end{aligned}
$$


Consequently since the previous result might show uneven values for each process and among the 4 global factors (Geometry, Appearance, Functionality, Mech. Properties), the 4 vectors are aggregated in a single matrix and then normalized by equation (4) to obtain the final normalized matrix Mn (5).

$$
\begin{gathered}
M n=\left[\begin{array}{llll}
N 11 & N 12 & N 13 & N 1 n \\
N 21 & N 22 & N 23 & N 2 n \\
N 31 & N 32 & N 33 & N 3 n \\
N 41 & N 42 & N 43 & N 4 n
\end{array}\right] \\
M n(i, j)=S(i, j) / \sum_{i=1}^{4}\left(M A p_{j}\right)
\end{gathered}
$$

A ranking procedure is needed to determine the order of the selected alternatives according to their suitability. Fuzzy sets are ranked by a number of different strategies (Byun and Lee, 2005, Lee-Kwang, 1999)). Mahesh (Mahesh, 2005) proposes to use the max-min method for a similar case in RP selection; however it had the disadvantage of being too predictable since the final raking was based on the Maximum weak-point of each process. Although the transformation method applied by Lan (2005) adds some complexity it may guide to a more robust ranking method therefore it'll be applied.

Let $W=(w 1, w 2 w 3, w 4)$ be the weighting value vector. The final ranking is obtained from equation (6).

$$
\text { Ranking }=M n * W=\sum_{j=1}^{n} M n j * W j
$$

This equation generates a single ranking value for each process where the vector W will be comprised of the user's criteria.

The final verification is performed by applying the CM vector. As described before, it is comprised by critical criteria introduced by the user. Its use will be illustrated in the following example.

\section{Case Study}

A number of case studies have been applied using the presented model. All cases correspond to real parts in this case mechanical elements designed by the CDEI (CDEI, 2008)design team. Through this investigation the impact of different parameters and design preferences have been evaluated on the final RM process ranking. One representative case is included below.

\section{Figure 11. 3D model of an internal mechanical part (a), and sand casted final part (b)}

CDEI was assigned the task to design a muscular relaxation device intended for the athlete's relaxation of the legs. Initial demand for the product was established in 500 units per year. Most of the internal parts were projected as sand casted elements due to lower cost for low volumes including the part shown in Figure 11 whose original design had to be modified in order to fulfil the restrictions imposed by sand casting (e.g. draft angles, constant wall thickness, avoid captured cavities, etc.). Furthermore the choice of sand casting included the difficult positioning of internal nucleus due to the design requirements.

The final part was made of Aluminium as shown in Figure 11b. However no critical functions had to be performed but the transmit ion of lineal movement. Therefore the part has two cylinders like troughholes, for 2 vertical bars. Since it is an internal part there is not surface finishing or appearance 
considerations. Tolerances are neither an issue, one of the main reasons for using sand casting. However two special aspects suggested that RM should be explored as an option:

1- The part performs a non-critical function, i.e. it does not bear important mechanical forces.

2- The hollow cylinders need a low friction coefficient. A well known polyamide attribute.

The RMADS interface was used for entering the appropriate values according to the part requirements. It shows the iterative selection made by the designers in order to evaluate different options for the design and the result ranking. (Figure 12)

Figure 12. Graphical User interface for the RMADS system

\subsection{Selection description}

Consider the info given in Figure 12 as the first data input according to the information available for the part. Note that Critical factors remained inactivated due to the nature of the function to be performed. Besides linguistic variables and numeric data, the weighting factors have been assigned through each box besides the categories shown in Table 3:

Table 3. Importance scale for the RMADS system

According to design requirements and the designer's criteria the Selective Laser Sintering (SLS) and Fused Deposition Method (FDM) would be possible alternatives to explore Figure 13a. Note that 3 important RP processes for aesthetical applications have been rule out, due to the critical requirement imposed for a maximum service temperature of at least $100^{\circ} \mathrm{c}$ that is difficult to withstand by materials for these processes.

On the other hand if we set Material type to "Metal" results would be as shown in figure 13b. For this case, Tolerance, Surface finish and Section thickness are not crucial therefore there's an imperceptible difference among the listed alternatives; however by "playing" with the parameters a more refined result can be achieved.

Figure 13. Final results given by RMADS

\subsection{Numerical example}

A demonstration with the data provided in the previous case study is shown below. Let $G(7)$ be the matrix that resulted from the selection made in figure 2 .

$$
\mathrm{G}(\mathrm{i}, \mathrm{j})=\left\{\begin{array}{cccccccccccc}
1 & 1 & 1 & 1 & 1 & 1 & 1 & 1 & 1 & 1 & 1 \\
1 & 0.75 & 0.75 & 0.85 & 0.85 & 0.75 & 0.75 & 0.85 & 0.85 & 0.75 & 1 \\
0.85 & 1 & 0.59 & 0.4 & 0.53 & 0.7 & 0.76 & 0.4 & 0.42 & 0.75 & 0.58 \\
1 & 0.26 & 1 & 0.56 & 1 & 0.19 & 0.93 & 0.47 & 0.56 & 0.37 & 0.93 \\
0.3 & 1 & 1 & 1 & 1 & 1 & 1 & 1 & 1 & 1 & 0.8 \\
0 & 0 & 0 & 0 & 1 & 0 & 0 & 0 & 1 & 0 & 1 \\
0 & 0 & 0 & 0 & 1 & 0 & 0 & 0 & 1 & 0 & 1 \\
0 & 0 & 0 & 0 & 1 & 0 & 0 & 0 & 1 & 0 & 1 \\
0.17 & 1 & 1 & 0.17 & 1 & 1 & 1 & 0.17 & 0.25 & 1 & 1
\end{array}\right\}
$$

Where $\mathrm{i}=$ Number of attributes selected. And $\mathrm{j}=$ number of processes compared. Then the matrix is divided into the four main categories as shown in the user interface where attributes pertaining to each category are added: 
As the final step let $\mathrm{W}=(\mathrm{w} 1, \mathrm{w} 2, \mathrm{w} 3, \mathrm{w} 4)$ be the vector corresponding to the weighting factor entered by the user. For this example $W=(0.333,0.108,0.666,0.892)$. By applying equation (6) the final ranking results are as shown in Table 4 . Note that as the last step, since the critical multiplier of "Max service Temperature" was activated; only those processes that survived this requirement are presented as a feasible option.

Table 4. Final ranking for the presented example

\section{Conclusions}

The proposed method contributes in filling the gap between conventional manufacturing knowledge and the actual knowledge on Rapid Manufacturing. Although the real value of the system will depend on the ability to feed the databases and monitor upcoming materials and new technology developments, it contains an appropriate logic for the selection or recommendation of a suitable RP/RM alternative.

While most of the RP equipments are being used as prototypes generators it is interesting to explore the possibility of approaching manufacture. Since every design case is different, what is normally an inappropriate process for a certain task may be a quite good candidate for another, as long as the critical constraints imposed by the designer are fulfilled.

The next step for developing a more robust RM Advice system is to integrate a cost analysis module. Although previous RP selector include the cost factor or weights according to self developed surveys, for real manufacture a qualitative estimate is not always useful and may not provide valuable information for a decision maker. Therefore current work is being developed to integrate a cost model which is able to perform calculations on economic-batch and single part costs. It may be a hybrid between parametric models and neural networks which have not been extensively applied to this field but have already shown great potential in other areas of fabrication.

\section{References}

ASERM (2006) Spanish Rapid Manufacturing Association.

ASHBY, M. (2005) Materials Selection in Mechanical Design, Oxford, Elsevier.

ASM (1997) ASM Handbook. Materials Selection and Design, Ohio, USA, ASM International.

BERNARD, A. (2003) An original approach for the memorisation and the generation of rapid product development processes. Rapid Prototyping Journal, 9, 58-67.

BIBB, R., TAHA, Z., BROWN, R. \& WRIGHT, D. (1999) Development of a rapid prototyping design advice system. Journal of Intelligent Manufacturing, 10, 331-339.

B0OTHROYD, G. P. D. (1883) Design for assembly: a designer's handbook, University of Massachusetts at Amherst.

BRECHET, Y., BASSETTI, D., LANDRU, D., SALVO, L. (2001) Challenges in materials and process selection. Progress in Materials Science, Volume 46, Pages 407-428.

BYUN, H. S. \& LEE, K. H. (2005) A decision support system for the selection of a rapid prototyping process using the modified TOPSIS method. International Journal of Advanced Manufacturing Technology, 26, 1338-1347.

CAMPBELL, R. I. \& BERNIE, M. R. N. (1996) Creating a database of rapid prototyping system capabilities. Journal of Materials Processing Technology, 61, 163-167. 
CARLSSON, C. A. F., R., (1996) Fuzzy multiple criteria decision making: recent developments. Fuzzy Sets and Systems, 139153.

CASTLE-ISLAND, C. (2007) Worldwide Guide to Rapid Prototyping.

CDEI, C. O. I. M. D. C. (2008) Design of a Muscular relaxation Machine.

CHEN, S.-M. (1997) A new method for tool steel materials selection under fuzzy environment. Fuzzy Sets and Systems, Volume 92, Number 3, 16 December 1997, 265-274(10).

CHEN, S. J. A. H., C.L (1992) Fuzzy multiple attribute decision making-methods and applications. Lecture Notes in Economics and Mathematical Systems.

DEWHURST, B. (2007) Design for Manufacturing and Asembly. Cost reduction Tools.

DIETER, G. E. (2000) Engineering Design: A materials and Processing Approach, Mc Graw Hill.

EFUNDA, I. (2007) Efunda Engineering Fundamentals.

GIACHETTI, R. E. (1998) A decision support system for material and manufacturing process selection. Journal Of Intelligent Manufacturing, 9, 265-276.

GRANTA, M. I. (2007) CES EduPack.

HELSINKI UNIVERSITY OF TECHNOLOGY (2002) RP Selector.

HORNBERGER, L. E. (1993) Rapid Prototyping Program. Santa Clara, California, Santa Clara University.

IVF SWEEDEN (2005) RP Selector.

JACOBS, P. R., DAVID (1992) Rapid Prototyping \& Manufacturing: Fundamentals of StereoLithography, Society of Manufacturing Engineers.

JIANG, B. C. \& HSU, C. H. (2003) Development of a fuzzy decision model for manufacturability evaluation. Journal of Intelligent Manufacturing, 14, 169.

LAN, H. (2005) Decision support system for rapid prototyping process selection through integration of fuzzy synthetic evaluation and an expert system. International Journal Of Production Research, 43, 169-194.

LEE-KWANG, H. (1999) A Method for Ranking Fuzzy Numbers and Its Application to Decision-Making. IEEE TRANSACTIONS ON FUZZY SYSTEMS, VOL. 7.

MAHESH, M. (2005) Benchmarking for decision making in rapid prototyping systems. 2005 Ieee International Conference On Automation Science And Engineering (Case), 19-24.

MASOOD, S. H. \& AL-ALAWI, M. (2002) The IRIS rapid prototyping system selector for educational and manufacturing users. International Journal of Engineering Education, 18, 66-77.

MASOOD, S. H. \& SOO, A. (2002) A rule based expert system for rapid prototyping system selection. Robotics and ComputerIntegrated Manufacturing, 18, 267.

MATHWORKS, I. (2006) Matlab R14.

MATWEB (2008) Online Materials Information Resource.

MICROSOFT (2005) Microsoft Office Access 2007.

MULLER, H., BAUER, J. AND KLINGENBERF (1996) Computer based rapid prototyping system selection and support. Proceedings of the Time Compression Technologies Conference. Gaydon, UK.

MUNGUÍA, J. (2007) Pursuing successful Rapid Manufacturing in a standards-less industry: a best practice approach. IN BARTOLO, J. B. (Ed.) Virtual and Rapid Manufacturing. Taylor \& Francis.

PHILLIPSON, D. K. A. H., M.R. (1997) Rapid prototyping machine selection programme. Proceedings of the 6th European Conference on Rapid Prototyping and Tooling. Nottingham, UK.

RAJ, P. A. \& KUMAR, D. N. (1999) Ranking alternatives with fuzzy weights using maximizing set and minimizing set. Fuzzy Sets and Systems, 105, 365-375.

RAO, R. V. \& PADMANABHAN, K. K. (2007) Rapid prototyping process selection using graph theory and matrix approach. Journal of Materials Processing Technology, 194, 81-88.

SHERCLIFF, H. R. \& LOVATT, A. M. (2001) Selection of manufacturing processes in design and the role of process modelling. Progress in Materials Science, 46, 429-459.

TEAMSET (2005) Manufacturing Analysis software.

ULLMAN, D. G. (1997) The Mechanical Design Process, New York, NY, McGraw-Hill.

WATERMAN, N. A., M. (1991) CRC-ELSEVIER Materials Selector Volume 1, Elsevir Science.

WOHLERS, T. T. (2006) Wohlers report 2006: rapid prototyping \& manufacturing state of the industry annual worldwide progress report / Terry T. Wohlers. Colorado: Wohlers.

ZIMMERMAN, H. J. (1991) Fuzzy Set Theory and its Applications, Boston,M.A USA, Kluwer. 


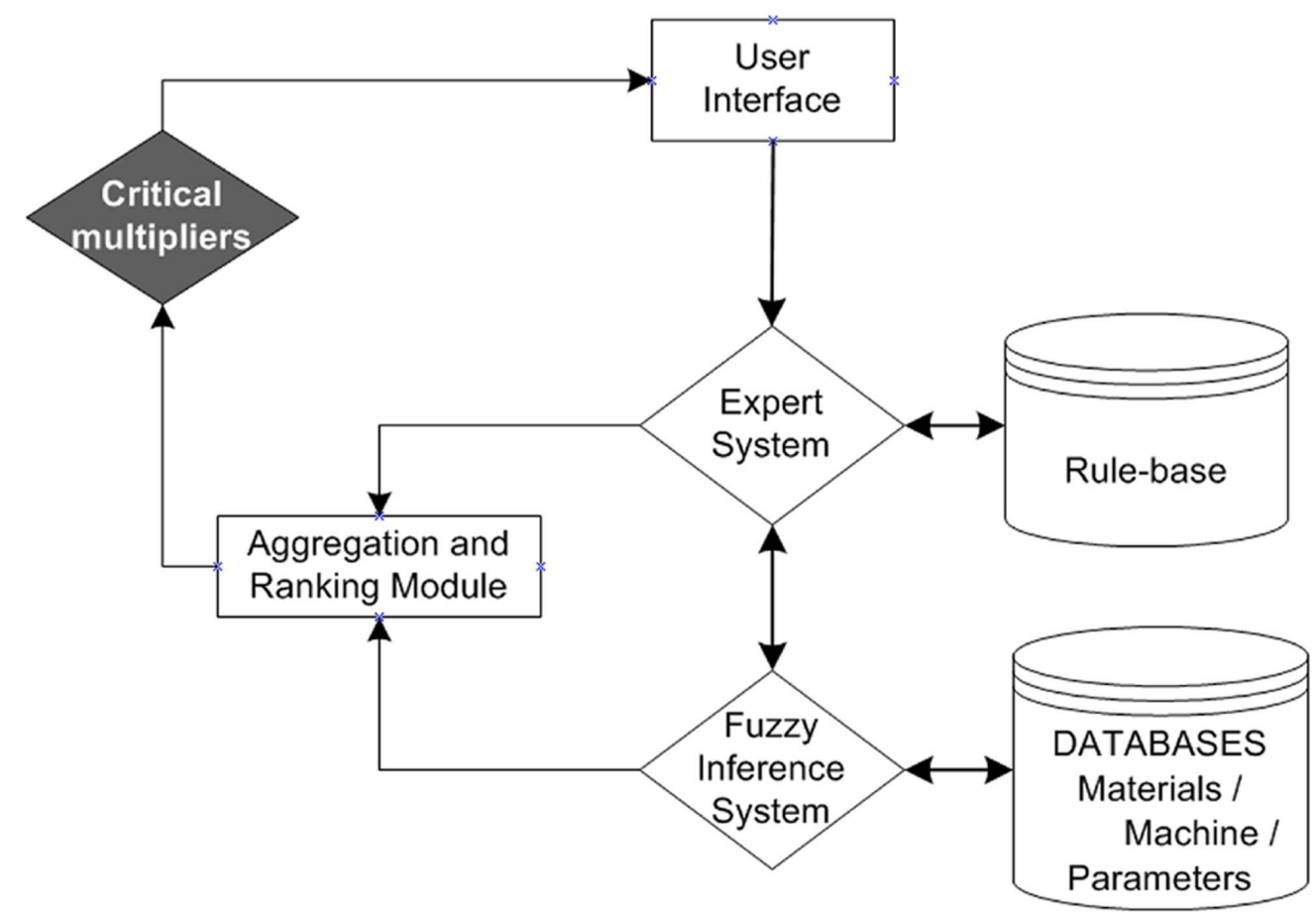

Figure 1. RMADS architecture and its main blocks $83 \times 60 \mathrm{~mm}(600 \times 600 \mathrm{DPI})$ 


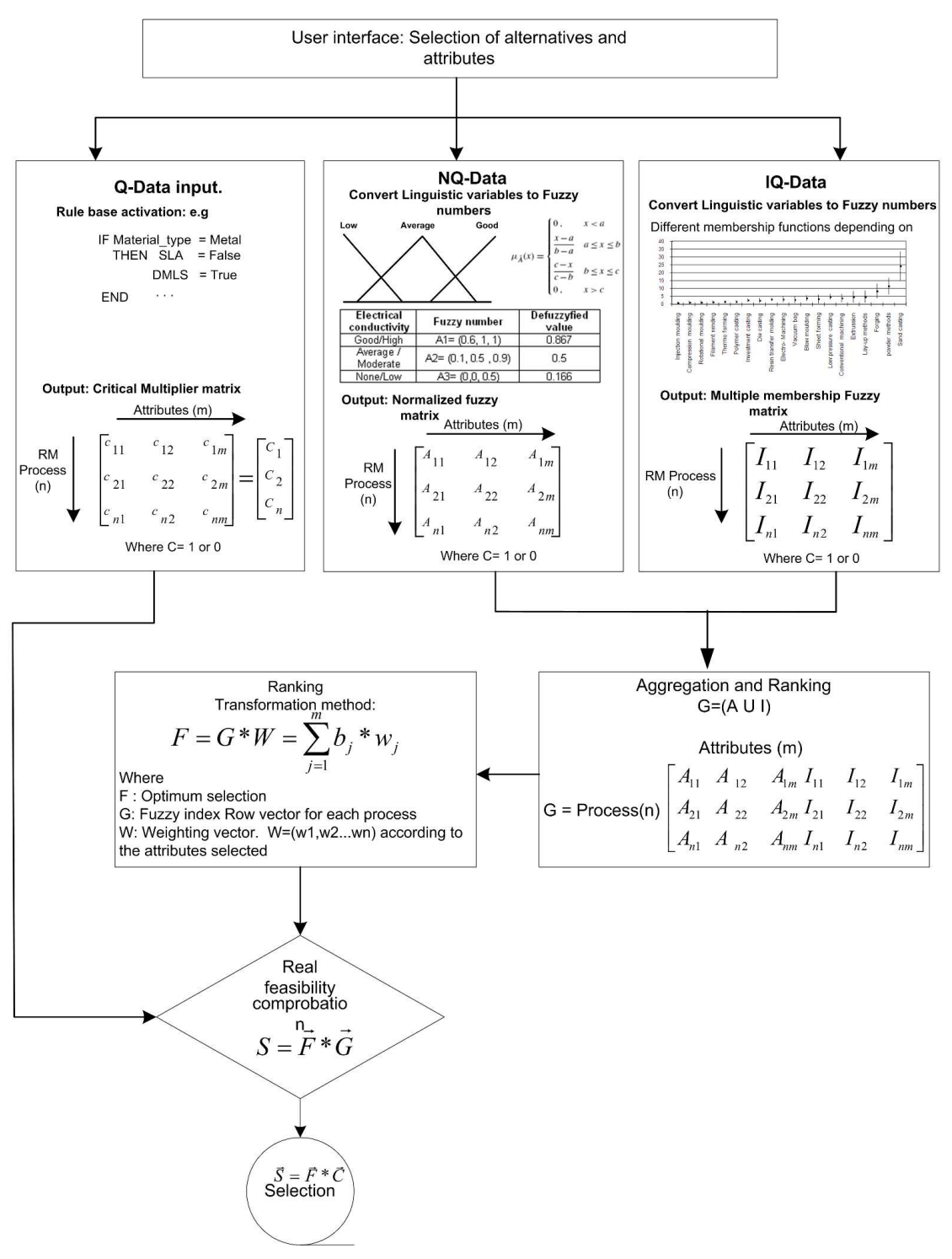

Figure 2. The proposed Rapid Manufacturing Advice System algorithm $152 \times 187 \mathrm{~mm}(600 \times 600 \mathrm{DPI})$ 
Figure 3 . The 4 main categories for parameter input and its data type $71 \times 33 \mathrm{~mm}(600 \times 600 \mathrm{DPI})$ 


\begin{tabular}{c}
\hline Part Xaxis $<$ Machine Xaxis \\
AND Part Y axis $<$ Machine Y axis \\
AND art Z axis $<$ Machine Z axis \\
THEN Machine $=$ TRUE \\
ELSE IF Part Volume $<$ (Machine build volume) \\
Machine $(n)=$ True \\
Print ("Consider slicing or sectioning the part") \\
ELSE Machine $(n)=$ FALSE \\
END
\end{tabular}

Figure 4. Sample rule for the expert system $71 \times 38 \mathrm{~mm}(600 \times 600 \mathrm{DPI})$ 
a)
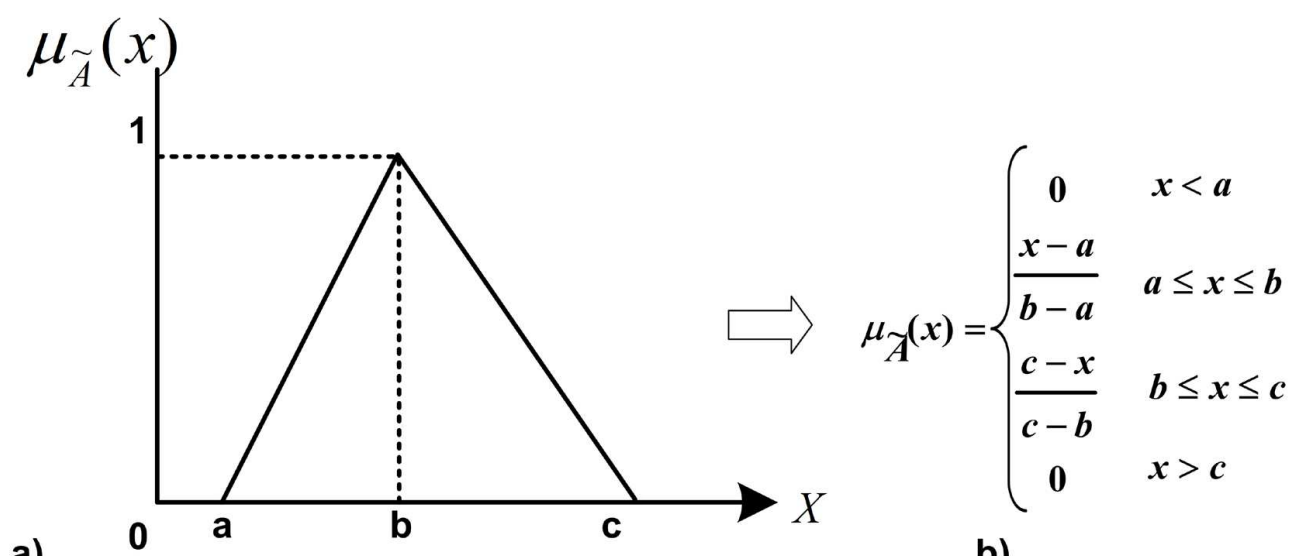

b)

Figure 5 Linguistic term converted to fuzzy numbers by means of a triangular membership $71 \times 32 \mathrm{~mm}(600 \times 600 \mathrm{DPI})$ 


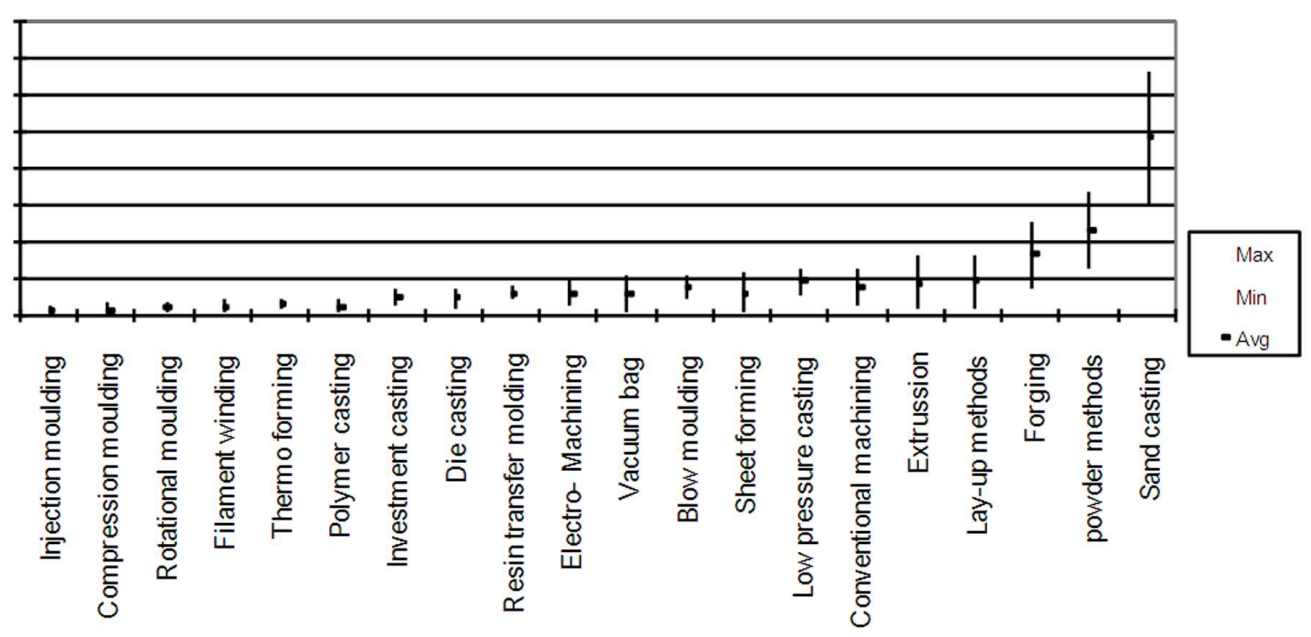

Figure 6. Tolerance levels for different conventional manufacturing routes $76 \times 38 \mathrm{~mm}(600 \times 600 \mathrm{DPI})$ 
Figure 7. Rapid Manufacturing options mapped on a similar scale as conventional manufacturing $76 \times 30 \mathrm{~mm}(600 \times 600 \mathrm{DPI})$ 


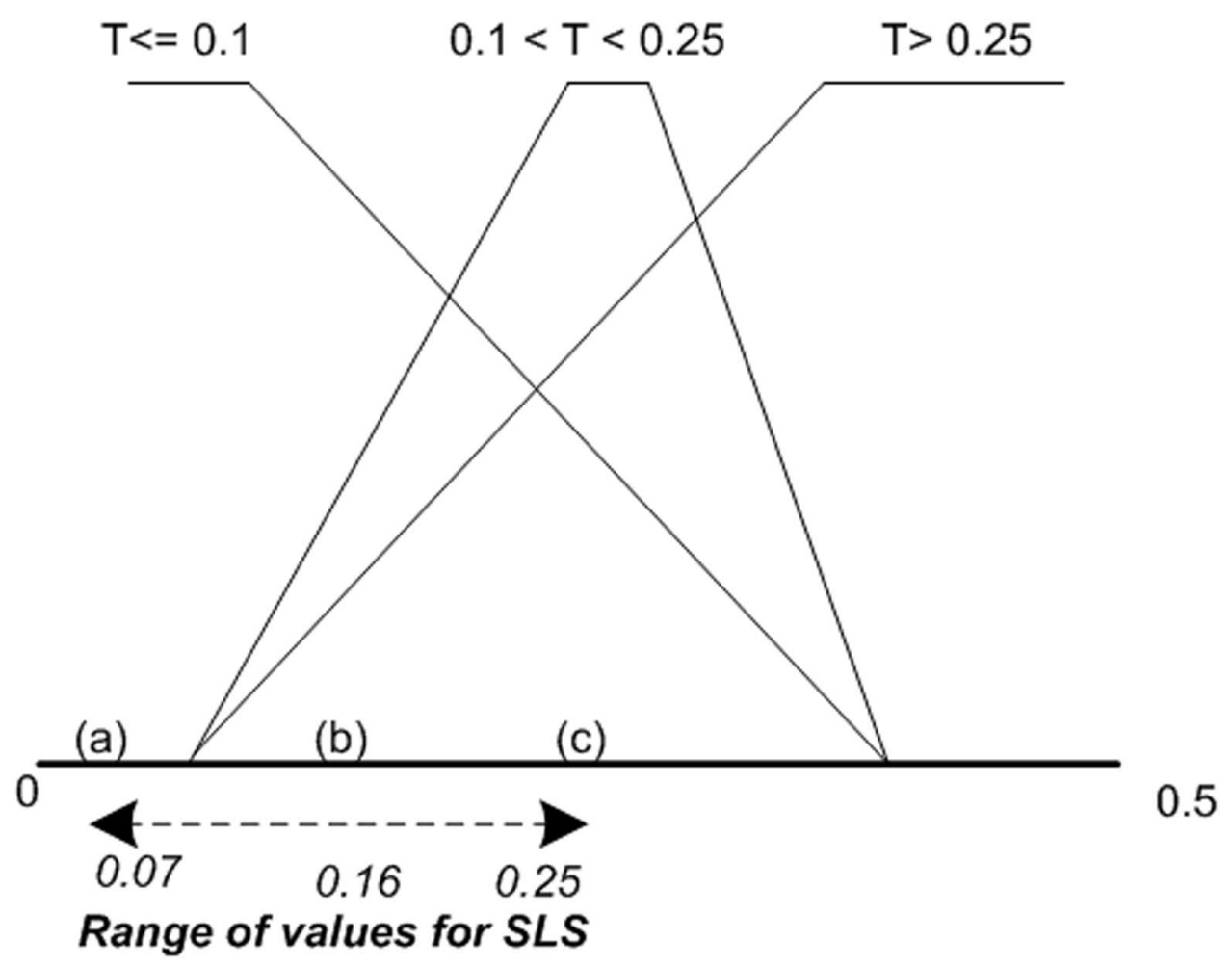

Figure 8. Trapezoidal membership function applied to Tolerance attribute range of SLS $68 \times 54 \mathrm{~mm}(600 \times 600 \mathrm{DPI})$ 
Number of attributes selected

Figure 9. Initial aggregated Matrix of fuzzy numbers $63 \times 28 \mathrm{~mm}(600 \times 600 \mathrm{DPI})$ 
Figure 10. Fuzzy number conversion for a 4 point scale $76 \times 28 \mathrm{~mm}(600 \times 600$ DPI $)$ 
Figure 11. 3D model of an internal mechanical part (a) $76 \times 46 \mathrm{~mm}(600 \times 600 \mathrm{DPI})$ 


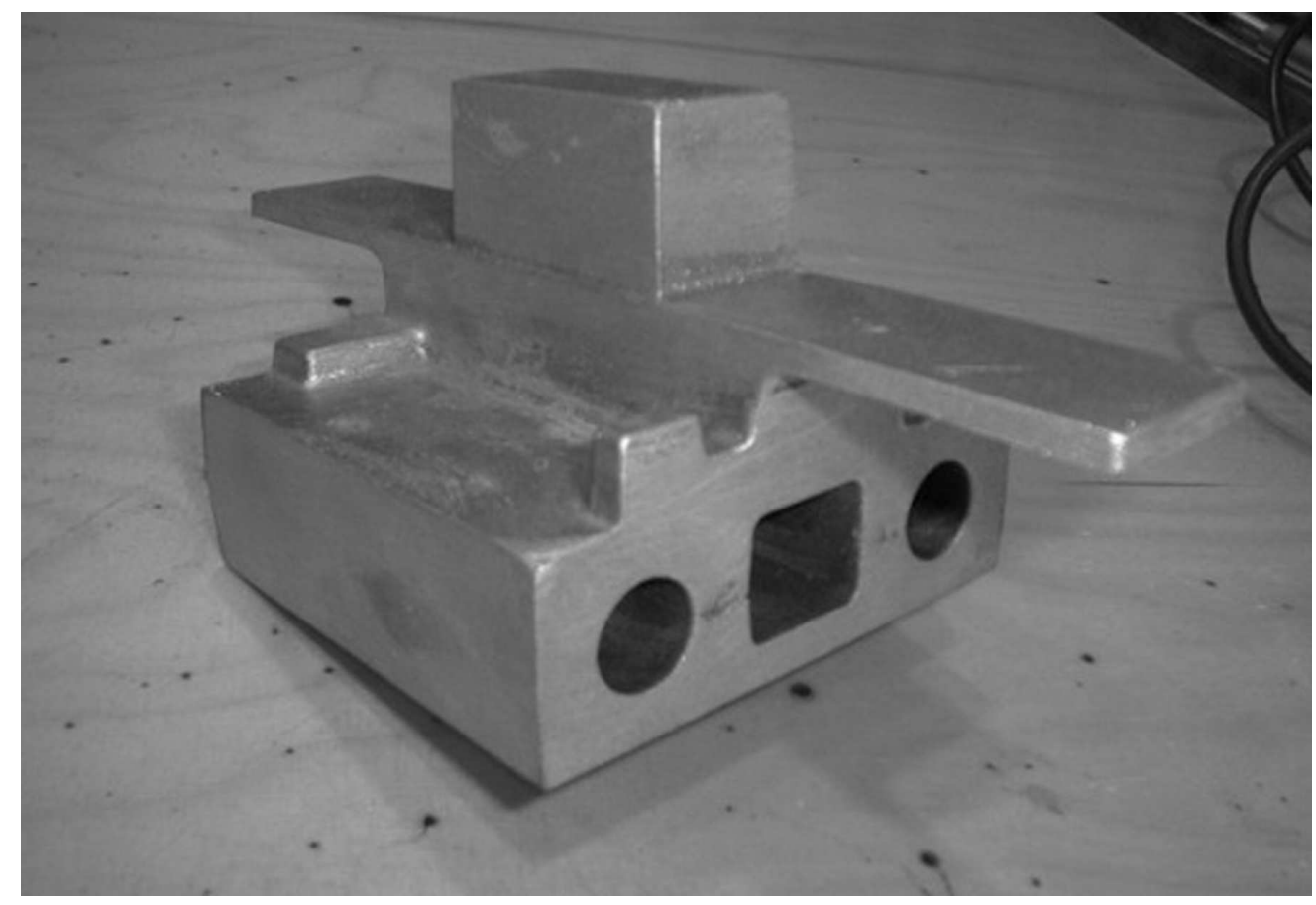

Figure 11(b) sand casted final part $76 \times 52 \mathrm{~mm}(600 \times 600 \mathrm{DPI})$ 


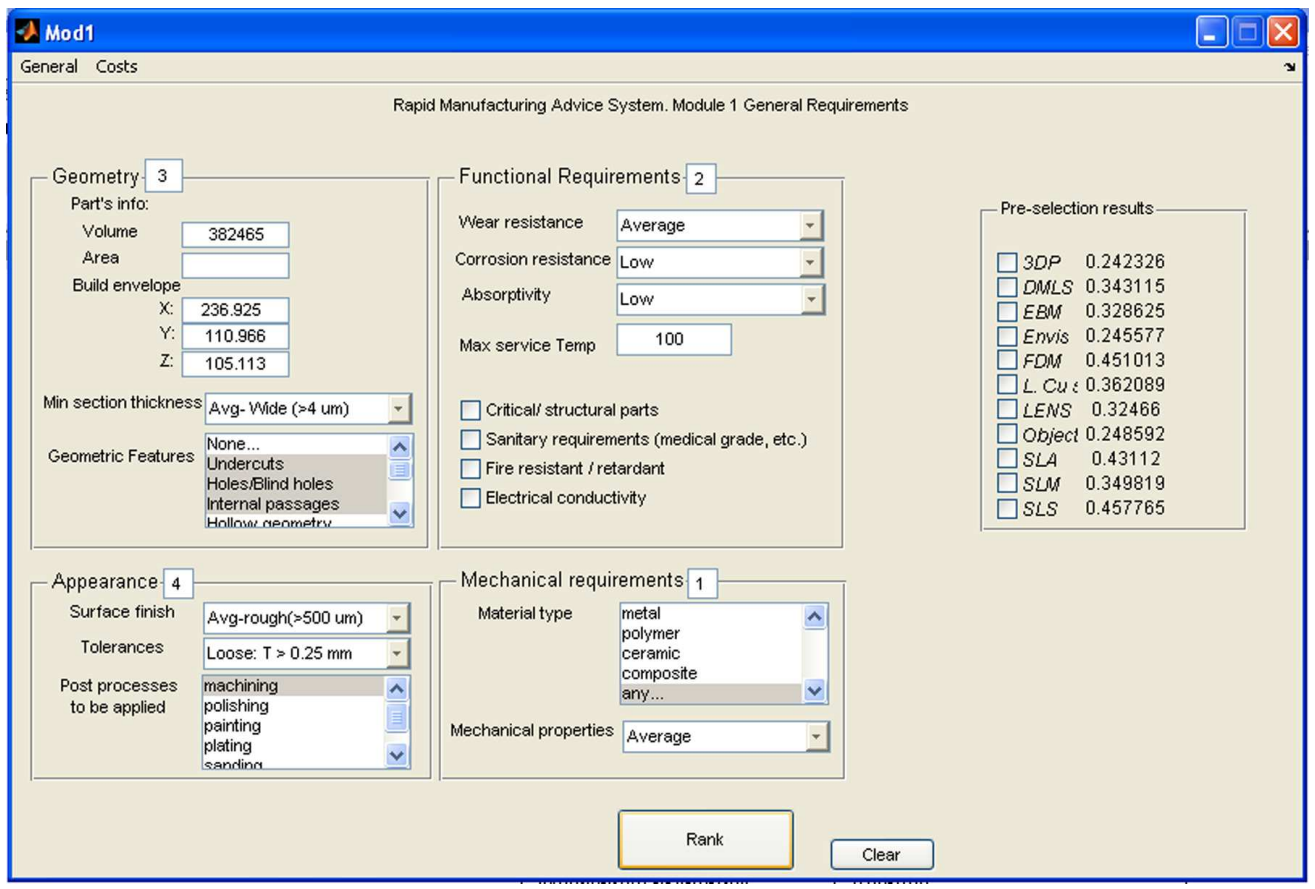

Figure 12. Graphical User interface for the RMADS system $152 \times 102 \mathrm{~mm}(600 \times 600 \mathrm{DPI})$ 


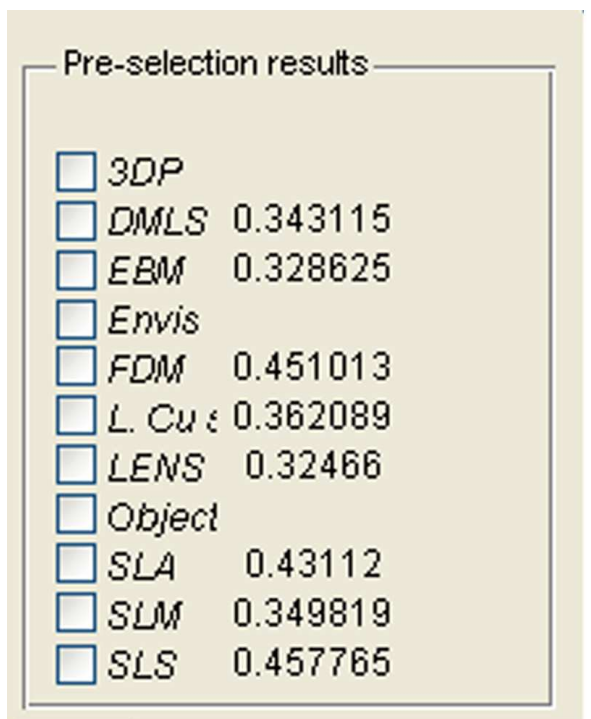

a)

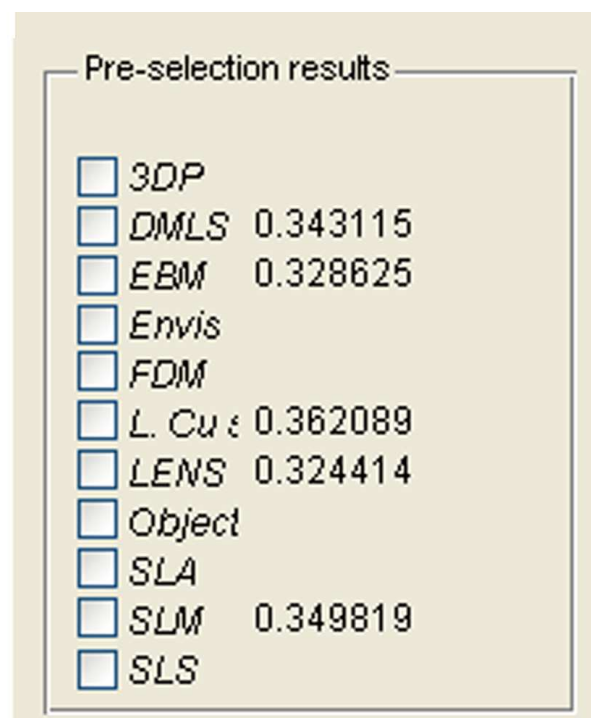

b)

Figure 13. Final results given by RMADS $76 \times 46 \mathrm{~mm}(600 \times 600 \mathrm{DPI})$ 


\title{
Development of an AI-based Rapid Manufacturing advice system
}

\author{
Javier Munguía $^{a^{*}}$, Joaquim Lloveras ${ }^{\mathrm{a}}$ Sonia Llorens $^{\mathrm{b}}$ and Tahar Laoui ${ }^{\mathrm{c}}$ \\ ${ }^{\mathrm{a}}$ Technical University of Catalonia, Barcelona Spain; ${ }^{\mathrm{b}}$ Industrial Equipment Research Centre (CDEI) Barcelona, Spain;, \\ ${ }^{\mathrm{c}}$ KFUPM, Mechanical Engineering Dept, Dhahran, Saudi Arabia
}

\begin{abstract}
The purpose of this paper is to assess the possibility of using Rapid Manufacturing (RM) as a final manufacturing route through a comparison of RM capabilities vs. conventional manufacturing routes. This is done by means of a computer-aided system intended to guide the designer in the selection of optimum production parameters according to general product requirements proper of the first design stages. The proposed system makes use of a number of Artificial Intelligence (AI) tools namely: fuzzy inference, relational databases and rule-based decision making to reach an optimum solution. A pilot application developed in Matlab® is presented to illustrate the system application on a real mechanical part used as case study.

Along the article it is shown how the proposed model may be useful for presenting feasible RM alternatives for parts and products not originally intended for additive manufacture. It also indicates when no RM alternatives are suitable for the given tasks, thus indicating those areas of knowledge which are necessary to expand in order to have at disposal comprehensive and reliable info on RM to compete with conventional processes.
\end{abstract}

Keywords: Rapid manufacturing, rapid prototyping, process selection, artificial intelligence

* Email: Javier.munguia@upc.edu 